\title{
FORMATION ENERGY AND ELECTRONIC STRUCTURE OF II-VI/IV SEMICONDUCTOR SUPERLATTICES
}

\author{
C. JĘDRZEJEK, J. KONIOR
}

Institute of Physics, Jagiellonian University, Reymonta 4, 30-059 Kraków, Poland

\author{
AND S. KAPRZYK
}

Institute of Physics and Nuclear Techniques, Technical University AGH

Al. Mickiewicza 30, 30-060 Kraków, Poland

We calculate formation energy and electronic structure of ultrathin (001) II-VI/IV semiconductor superlattices using the Korringa-Kohn-Rostoker all-electron method. Formation energies $(\Delta H)$ are $2.18 \mathrm{eV}$ for $\left(\mathrm{Ge}_{2}\right)_{1}(\mathrm{ZnSe})_{1}$ and $1.50 \mathrm{eV}$ for $(\mathrm{ZnS})_{1}\left(\mathrm{Si}_{2}\right)_{1}$. The results of this work are significantly different from these by Ferraz and Srivastava who obtained $\Delta H=0.88 \mathrm{eV}$ for $(001)\left(\mathrm{Ge}_{2}\right)_{1}(\mathrm{ZnSe})_{1}$ and moreover the one-layer superlattices are metallic, which confirms the results by Ohno and Ito. The large formation energies surely lead to interfacial instability.

PACS numbers: 73.20.Dx

With regard to structural properties, semiconductor superlattices (SLs) can be classified with regard to two types of features: (1) chemical nature, isovalent SL ( $\mathrm{Si} / \mathrm{Ge}, \mathrm{AlAs} / \mathrm{GaAs}, \mathrm{InAs} / \mathrm{GaAs})$ and heterovalent $\mathrm{SL}(\mathrm{Ge} / \mathrm{GaAs}, \mathrm{Si} / \mathrm{ZnS}$, $\mathrm{Ge} / \mathrm{ZsSe}, \mathrm{RbF} / \mathrm{GaAs}$ ); (2) difference of lattice constants of constituents, lattice mismatched ( $\mathrm{Si} / \mathrm{Ge}, \mathrm{Si} / \mathrm{GaAs}$, InAs/GaAs) and (nearly) lattice matched (Ge/GaAs, AlAs/GaAs, Si/ZnS, Ge/ZsSe, RbF/GaAs).

This work is concerned with a strongly polar matched SL with hope to apply it to silicon based technology: Si-ZnS structures. Using a self-consistent Korringa- Kohn-Rostoker all-electron method [1], we performed the ab initio band structure calculations for ultrathin (001) II-VI/IV semiconductor superlattices (SL) $(\mathrm{ZnS})_{1}\left(\mathrm{Si}_{2}\right)_{1}$ and $\left(\mathrm{Ge}_{2}\right)_{1}(\mathrm{ZnSe})_{1}$. The structure is shown in Fig. 1.

The one-particle Schrödinger equation was solved with the assumption that there is a muffin tin (MT) sphere around each ion such that the effective one-particle crystal potential may be assumed as being spherically symmetric inside the MT spheres. There were also additional "empty" muffin-tin spheres introduced in order to fill the empty space between the ionic MT spheres. To calculate the wave function, the spherical function expansion was used; the expansion was truncated at $l_{\max }=2\left(l_{\max }=1\right)$ for the "ionic" ("empty") MT spheres. The core electrons 


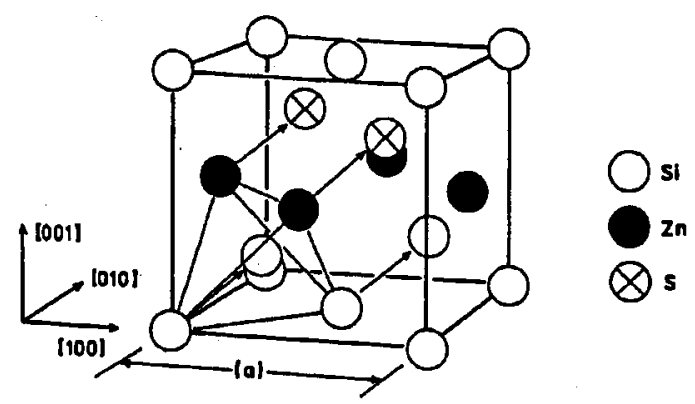

Fig. 1. Structure of the $(\mathrm{ZnS})_{1}\left(\mathrm{Si}_{2}\right)_{1}$ superlattice.

were treated in a fully relativistic way, while for the valence electrons a semirelativistic approach was applied. The self-consistency criterion was that the difference between the input and output potential should be smaller than $0.001 \mathrm{Ry}$. The restricted geometry optimization which consisted in the overall change of a lattice constant in $z$-direction and the change of IV-anion (cation-IV) bond lengths were performed.

The aim of calculations was to compare these structures with less polar III-V/IV superlattices by calculating mainly the band-structures and formation energies $\Delta H$ (given here for $\left.\left(\mathrm{Ge}_{2}\right)_{n}(\mathrm{ZnSe})_{n}\right)$

$$
\Delta H=E\left[\left(\mathrm{Ge}_{2}\right)_{n}(\mathrm{ZnSe})_{n}\right]-\frac{n}{2}\left\{E\left[\left(\mathrm{Ge}_{2}\right)_{1}\left(\mathrm{Ge}_{2}\right)_{1}\right]+E\left[(\mathrm{ZnSe})_{1}(\mathrm{ZnSe})_{1}\right]\right\} \text {. }
$$

The most systematic studies of Zunger's [2, 3], Kleinman's [4] and Ohno's groups [5, 6] for III-V/IV superlattices showed that the formation energy models work only for limited set of structures but qualitatively explain major trends for heterovalent superlattices:

1. $\Delta H(001)>\Delta H(110)>\Delta H(111)$ - the (111) superlattice is the least unstable,

2. minimization of the number of anion-anion (cation-cation) bonds,

3. to prevent charge flow swaps of atoms are favorable which is harmful for atomic sharpness.

Nevertheless, some basic discrepancies among these calculations underline difficulties and uncertainties of present electronic calculations.

The results of our calculations are presented in Figs. 2 and 3 (band structures) and in Table. The formation energies are much larger than for III-V matched polar superlattices (as compared to $0.4 \mathrm{eV}$ for the (001) growth for $\mathrm{Ge} / \mathrm{GaAs}$ ). This makes the ordered (001) growth of Si-ZnS impossible. On the other hand, it is known that the (111) growth of Si-ZnS leads to highly undesirable twinning. The important result is that the one-layer SLs are metallic, which confirms the results by Ohno and Ito $[5,6]$ but is in contradiction to less sophisticated calculations of Ferraz and Srivastava [7] who obtained $\Delta H=0.88 \mathrm{eV}$ for (001) $\left(\mathrm{Ge}_{2}\right)_{1}(\mathrm{ZnSe})_{1}$. It should be mentioned that the standard ab initio pseudopotential method with plane waves, for which only a few $q$ special points are used, 


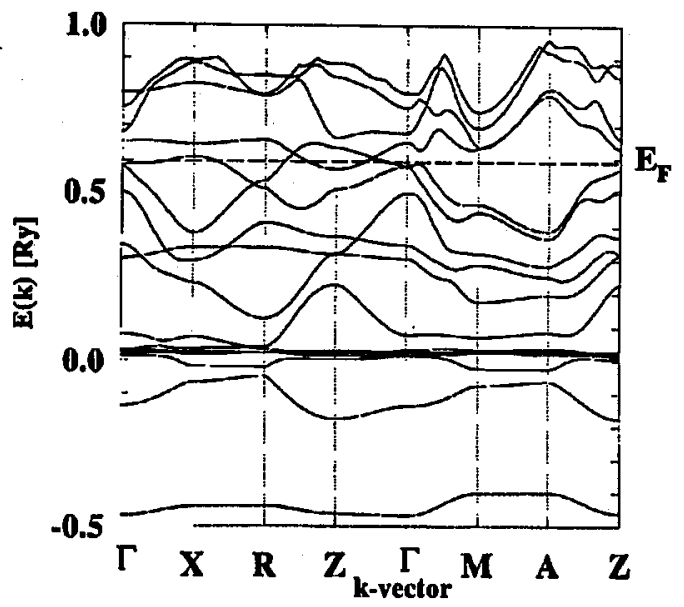

Fig. 2. Band-structure of the $(\mathrm{ZnSe})_{1}\left(\mathrm{Ge}_{2}\right)_{1}$ 1-layer superlattice $\left(E_{\mathrm{F}}=0.5900 \mathrm{Ry}\right)$.

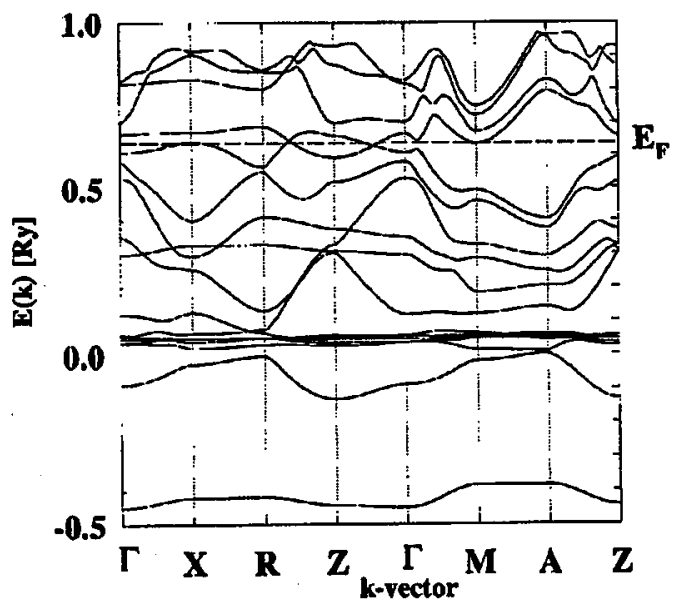

Fig. 3. Band-structure of the $(\mathrm{ZnS})_{1}\left(\mathrm{Si}_{2}\right)_{1}$ 1-layer superlattice $\left(E_{\mathrm{F}}=0.6365 \mathrm{Ry}\right)$.

would miss details around the Fermi surface and likely lead to a semiconductor rather than to a metallic structure.

In near future we intend to study few-layer superlattices in different structures (with swapped atoms). Preliminary results indicate a convergence difficulty of the KKR methods for these structures.

This work was supported by the US-Poland Skłodowska-Curie Fund grant MEN/NSF/92-116, by the NSF Heterostucture Synthesis of Silicon-Based Materials for Quantum Electronics, and by the grants no. PB 2603/2 of the State Committee for Scientific Research (Republic of Poland). 
Results of several calculations for (001) (II-VI $)_{1}\left(\mathrm{IV}_{2}\right)_{1}$ SL.

TABLE

\begin{tabular}{|c|c|c|c|c|}
\hline $\begin{array}{c}(\mathrm{II}-\mathrm{VI})_{1} \\
\left(\mathrm{IV}_{2}\right)_{1} \mathrm{SL} \\
\end{array}$ & Calc. method & $\begin{array}{l}\text { Optim. geometry } \\
\text { bond length change }\end{array}$ & $\begin{array}{l}\Delta H \\
{[\mathrm{eV}]}\end{array}$ & Gap \\
\hline$(\mathrm{ZnSe})_{1}\left(\mathrm{Ge}_{2}\right)_{1}$ & FS [7] & Zn-Ge incr. $8 \%$ & 0.88 & Sem. \\
\hline$(\mathrm{ZnSe})_{1}\left(\mathrm{Ge}_{2}\right)_{1}$ & $\begin{array}{l}\text { local emp. pseudop. } \\
\text { Ohno, Ito [5] }\end{array}$ & $\begin{array}{c}\text { Ge-Se decr. } 5 \% \\
\text { unknown }\end{array}$ & 1.54 & $\mathbf{M}$ \\
\hline & $a b$ initio and loc. pseud. & & & \\
\hline$(\mathrm{ZnSe})_{1}\left(\mathrm{Ge}_{2}\right)_{1}$ & $\begin{array}{c}\text { JKK (this work) } \\
\text { KKR }\end{array}$ & $\begin{array}{l}\mathrm{Zn}-\mathrm{Ge} \text { decr. } 2 \% \\
\text { Ge-Se incr. } 2 \%\end{array}$ & 2.18 & M \\
\hline$(\mathrm{ZnS})_{1}\left(\mathrm{Si}_{2}\right)_{1}$ & $\begin{array}{c}\text { JKK (this work) } \\
\text { KKR }\end{array}$ & does not change & 1.50 & M \\
\hline
\end{tabular}

\section{References}

[1] J. Korringa, Physica 13, 392 (1946); W. Kohn, N. Rostoker, Phys. Rev. 94, 1111 (1954); S. Kaprzyk, preprint, Academy of Mining and Metallurgy, Kraków, 1982.

[2] R.G. Dandrea, J.E. Bernard, S.-H. Wei, A. Zunger, Phys. Rev. Lett. 64, 36 (1990).

[3] R.G. Dandrea, S. Froyen, A. Zunger, Phys. Rev. B 42, 3213 (1990).

[4] R.S. Lee, D.M. Bylander, L. Kleinman, Phys. Rev. B 41, 10264 (1990).

[5] T. Ohno, T. Ito, Phys. Rev. B 47, 16332 (1993).

[6] T. Ohno, Solid State Commun. 74, 7 (1990).

[7] T. Ferraz, G. Srivastava, Semicond. Sci. 8, 67 (1993). 